\title{
Research and Practice of Bilingual Teaching Model Based on Flipped Classroom: A Case Study of Recruitment and employment
}

\author{
Yuan Fu \\ Wuhan Business University, Wuhan, 430056, China \\ email:627356365@qq.com
}

Keywords: Bilingual teaching model; Flipped classroom; Recruitment and employment

\begin{abstract}
The flipped classroom is a new type of teaching model that has swept the world over recent years. With the help of modern information technology, flipped classroom overturns the traditional teaching mode, highlighting self-study and defining the education by study. In this way, it gives top priority to the classroom teaching reform. This research, based on the curriculum characteristics of "recruitment and employment" and the major issues in teaching, explores the feasibility of flipping classroom, the concept of local practice and its values. It implements the flipped classroom mode of localized "Recruitment and employment" including three stages -before classroom, classroom and after-school, two-way effort from teachers and students. The establishment of an information platform targeting students' learning provides some ideas for realizing the combination of the flipped classroom and the course -- recruitment and employment.
\end{abstract}

\section{Introduction}

Recruitment and employment is vital to students majoring in human resource management. The purpose of this course is to allow students to systematically master the basic theoretical knowledge and operation skills of recruiting and hiring. Therefore, after graduation they can independently complete the recruitment and hiring of employees by combining the actual conditions of a company. Recruitment and employment play an increasingly important role in teaching and actual recruitment. Therefore, we should give priority to the way to choose scientific and effective teaching methods to increase teaching effectiveness.

\section{Features of Recruitment and employment}

Recruitment and employment with strong practicality and high application not only requires students to master the basic theories of Recruitment and employment, but also to learn specific practical skills. This course involves broad knowledge, so if we hope truly master it we need master the knowledge of management and integrate knowledge such as human resources management, psychology, behavior, interpersonal communication skills and labor contract law. For students lacking practical experience, this course is relatively abstract and difficult to understand. Therefore, it is necessary to effectively carry out participatory and experiential teaching activities in teaching practice, and introduce some real work situations into the classroom as a way to help students master the basic theory and operation skills of Recruitment and employment through interaction and participation of simulated interview.

\section{Major Problems in the Teaching of Recruitment and employment}

As one of the traditional six modules of human resource management, the Recruiting and employment course plays an irreplaceable role in the teaching of human resources management. On the one hand, it is an important part of the comprehensive training and improvement of the knowledge system of professionals. On the other hand, it is also an important part of strengthening professionals' knowledge in practical education. According to this course, students will be able to grasp all aspects of the company's recruitment process, and be familiar with the tasks and work 
methods of each link thus improving students' future employment competitiveness. In terms of the nature of the course, it emphasizes application and practice, but the following problems are still found in the current teaching process:

\subsection{Limitations of the Single Interactive Mode of Teaching to Classroom}

In the process of teaching, Recruitment and recruitment still adopts the traditional classroom teaching method. Under the influence of the traditional teaching model, the interaction between teachers and students is relatively limited, and the enthusiasm of students to participate is not high. Though teachers will take some diversified teaching methods such as role simulation, case analysis, simulated recruitment according to the relevant courses, this single interaction mode is unable to achieve the desired results due to the constraints of classroom environment, authenticity and time as well as inadequate students' participation and prepared activities. Especially for highly operational courses such as Recruitment and employment, students only pay attention to books, making it difficult for them to really contact the company's real recruitment activities, let alone applying the theory to practice. This single interaction model greatly limits the effectiveness of the classroom and is also detrimental to students' development and bad for promoting their own professional capabilities.

\subsection{Lack of Internship Platform and the Form of Training Education Form Outweigh Its Content}

Faced with the vigorous rise of the human resources management, most colleges and universities have kept up with the pace of the times in terms of the development of human resources management. However, in the teaching process, it still pays more attention to theory rather than practice and the reasons here are definitely numerous. On the one hand, under the influence of traditional teaching experience, the current teaching ideas and teaching concepts mostly focus on the mastery of the students' theoretical knowledge and the scores obtained by the test; on the other hand, the funding problem in the construction of the human resource management profession appears to be severe. Most colleges and universities have inadequate funds, especially for private colleges that rely exclusively on their own strength. Of course, with the change of educational concepts, many colleges and universities have also realized the importance of the cultivation of students' practical ability. Therefore, advancing the construction of professional training rooms has also become the main task of many colleges and universities.

However, judging from the current situation, most colleges and universities in the human resources management training room will still face the difficult problem of transforming the theory into technology when setting up practical training courses. Most training rooms still focus on the hardware such as well-equipped computers and networks connection and they neglect the training of contents during the actual training process. As a result, in the current practical training, only the knowledge in the classroom is moved to the computer, and the value of the training room is not truly reflected. Without real work environment, it is difficult to train students' ability to work and to truly accomplish the transformation and migration of "theory to skill" in the teaching process.

\subsection{Narrow Teaching Channels and Limited Information Acquisition}

From the traditional teaching concept, most classrooms generally follow an interactive model of "teacher-student”. In such a teaching model, teachers become the main source of students' obtaining self-confidence in learning. In this environment of learning dependence, it is not conducive to cultivate students' awareness and ability for independent learning, thus unable to effectively mobilize the enthusiasm of students to participate in curriculum practice. At the same time, as teachers are mainly engaged in theoretical teaching and scientific research, they are also somewhat lacking in cultivating students' technical skills. On the other hand, the theoretical teaching of the school always lags behind the development of the times and the needs of enterprises. When the school education cannot break through the pyramids of universities and is unable to pay attention to learn from the outside world, the students who are trained by schools are bound to digress away from society, enterprise, causing students unable to adjust their role after graduation quickly. 


\section{Proposal of Bilingual Teaching Mode Based on Flipped Classroom}

Faced with the various problems in the teaching process of the Recruitment and employment and combined with the current enterprise's quality and ability requirements for graduates of human resources management. [1] This paper proposes the model of bilingual teaching based on flipped classrooms according to the characteristics of the Recruitment and employment and the logical structure of knowledge with a view to adjusting the original teaching model focusing on the theory as a way to cultivate professional and technical talents. The output of the flipped classroom has witnessed the reform and innovation of teaching methods and methods under the information age. Traditional teaching includes knowledge transfer and internalization. [2] The flipped classroom is a way of turning the fixed mode featuring that teachers teach in the classroom and students finish homework after school under the traditional teaching mode into knowledge transfer through information technology featuring that students complete these outside class. The internalization of knowledge is a new model that is jointly completed by the classmates and the guidance of the teacher in the class. [3] The flipped classroom creates the environment of self-study before class, breaks the 45-minute limit of regular teaching activities and extends the class outside the classroom. It makes use of the Internet and information technology to complete the knowledge transfer before class, reduce the occupancy of class time, so students have sufficient time in the classroom to complete project practice activities, solving the problem of limited time for project-based teaching. Students complete self-study before class, use learning resources library to freely choose their own learning schedule, and use information technology to interact with teachers to solve difficult problems. [4] By this way, students have become self-paced learners and become the main body of teaching activities.

\section{Design Concept of Flipped Classroom of Recruitment and Employment}

According to the implementation structural model, as shown in Figure 1, we have made preparations for the combination of flipped classroom and project-based teaching from the following three aspects. [5]

\subsection{The Self-study before Class}

The flipped classroom pays attention to student's self-directed learning, so teachers are required to do a lot of preparatory work before class, including determining the teaching content and objectives of each work task, providing students with task guides and rich exercise materials before class. Teachers should make use of Internet resources to select supplementary network materials for students. What's more, teachers can also create corresponding teaching videos on their own.

\subsection{The Classroom Interactive Learning}

We should apply the concept of flipped classrooms to project-based teaching. Teachers and students learn through exchanges and solve the doubts encountered before independent learning and promote students' internalization of knowledge. The students complete the task in the form of group cooperation, display and share the results in the classroom, discuss and evaluate each other, so as to improve the students' knowledge application ability. The flipped classroom reduces the time for teachers to teach in the classroom and solves the problem of project-based classroom teaching that lacks adequate time. Therefore, the time is used to organize students to display results, exchange completing experience of projects, and a small part is used to solve students' problems encountered before class.

\subsection{The Feedback Evaluation after Class}

The flipped classroom needs to be extended to after class and students learn and summarize the experience of the learning acquisition. Teachers and students can make full use of the WeChat group, QQ group and other information exchange platforms to conduct in-depth discussions and exchanges, consolidating and deepening students' cognition as a way to accumulate richer material for teachers' follow-up teaching. 


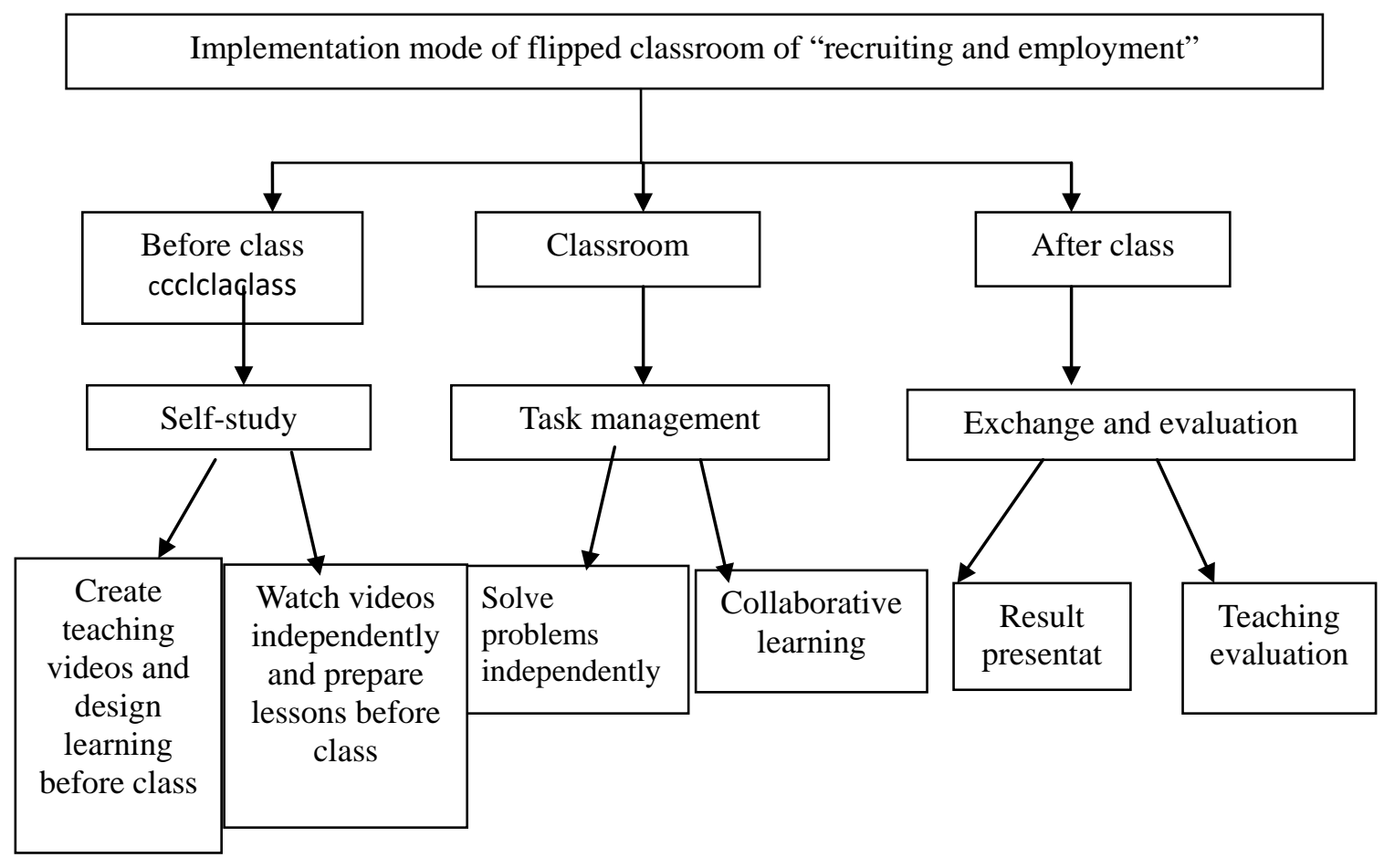

Figure 1 Implementation Mode of Flipped Classroom of “Recruiting and employment

\section{Conclusions}

The flipped classroom is both an opportunity and a challenge. In the teaching of Recruitment and employment, it is necessary to focus on how to engage in flipping teaching, how to evaluate the flipped classroom teaching and other basic issues. It can be said that it needs reflection and further exploration. From the perspective of front-line teachers and researchers, the author introduces the concept of flipped classroom into the teaching reform of the Recruitment and employment. It is a useful attempt and a positive exploration. In practice, it will inevitably encounter some problems and setbacks. On the one hand, the teaching model and concept of flipped classrooms need to be further improved; on the other hand, we need to consider how to design according to model science, complete a series of steps and implement targeted measures for curriculum systems, thus truly promoting the development of students.

\section{Acknowledgements}

In this paper, the research was sponsored by Wuhan Business University, and the Project Name is Research and Practice of Bilingual Teaching Model Based on Flipped Classroom: A Case Study to Recruitment and employment (Project No.2017096).

\section{References}

[1] The learning-teaching nexus: modelling the learning-teaching relationship in higher education[J]. Bernadette Knewstubb. Studies in Higher Education. 2016 (3)

[2] The experience of three flipped classrooms in an urban university: an exploration of design principles[J]. Min Kyu Kim, So Mi Kim, Otto Khera, Joan Getman. The Internet and Higher Education. 2014

[3] Looking at the Impact of the Flipped Classroom Model of Instruction on Undergraduate Multimedia Students at CSUN[J]. Jacob Enfield. TechTrends. 2013 (6)

[4] How learning in an inverted classroom influences cooperation, innovation and task 
orientation[J]. Jeremy Strayer. Learning Environments Research. 2012 (2)

[5] Examining the multidimensionality of approaches to learning through the development of a revised version of the Learning Process Questionnaire. Kember David, Biggs John, Leung Doris Y P. The British journal of educational psychology. 2004 